\title{
Ontogenetic conflicts and rank reversals in two Mediterranean oak species: implications for coexistence
}

\author{
Ignacio M. Pérez-Ramos ${ }^{1 *}$, Itziar R. Urbieta ${ }^{2}$, Miguel A. Zavala ${ }^{3,4}$ and Teodoro Marañón ${ }^{1}$ \\ ${ }^{1}$ IRNAS, CSIC, PO Box 1052, Sevilla 41080, Spain; ${ }^{2}$ Departamento de Ciencias Ambientales, Universidad de Castilla- \\ La Mancha, Av. Carlos III s/n, Toledo 45071, Spain; ${ }^{3}$ CIFOR-INIA, ctra. de la Coruña, Km. 7.5, Madrid 28040, Spain; \\ and ${ }^{4}$ Departamento de Ecología, Universidad de Alcalá, Alcalá de Henares, Madrid 28871, Spain
}

\section{Summary}

1. In heterogeneous environments, species segregate spatially in response to selective abiotic and biotic filters occurring throughout plant ontogeny. Ontogenetic conflicts in recruitment may lead to spatially discordant patterns of regeneration among microhabitats with different plant cover. In addition, species differing in seed size may be subjected to opposing ecological and evolutionary pressures throughout the life cycle of the plant.

2. We used a multi-stage demographic approach aimed at characterizing the main stage-specific probabilities of recruitment (seed survival, seed germination, seedling emergence and survival during the first 3 years of life) in two Mediterranean oak species coexisting at southern Spain. We calibrated linear and nonlinear likelihood models for each of these consecutive life history stages and calculated overall probabilities of recruitment along a wide range of plant cover and seed size variation.

3. Seed predation and seedling mortality over the dry season were the most limiting processes for the two studied oak species. However, species ranking diverged substantially through the life history stages considered in this study due to different ontogenetic trends among species.

4. At the intraspecific level, recruitment-driving processes during the seed and the seedling stages showed opposing tendencies along the explored range of plant cover and seed size. Thus, small-sized acorns and open areas were favoured for the seed stage, whereas large acorns and dense microhabitats did for the seedling stage.

5. The existence of opposing selective pressures on seed mass and their differential influence on the two studied oak species determined the occurrence of species-specific optimal seed sizes (small acorns for Quercus canariensis vs. acorns of large or intermediate size for Quercus suber).

6. The spatial patterns predicted by our overall-recruitment models provided some evidence of regeneration niche partitioning in the two coexisting oak species, supporting their current distribution patterns as saplings and adults at the study area.

7. Synthesis. We conclude that within- and among-species differences through plant ontogeny, arising from species differential response to microhabitat heterogeneity and seed size variation, could be of great importance for oak species niche segregation, driving stand dynamics and spatial pattern distribution along the landscape. The information provided by this study could be also applied to optimize management and restoration programmes since it has enabled us to identify the most favourable conditions and traits for recruitment in oak species that exhibit serious constraints for natural regeneration.

Key-words: Mediterranean forest, plant cover, Quercus canariensis, Quercus suber, regeneration niche, reproductive ecology, seed size, seed-seedling conflict 


\section{Introduction}

In heterogeneous environments, such as Mediterranean-type forests, species segregate spatially in response to selective abiotic and biotic filters occurring throughout plant ontogeny (Grubb 1977; Nathan \& Muller-Landau 2000). In most longlived plant populations, these environmental sieves play an extensive role in determining species distribution during early life history stages (Ricklefs 1977; Kitajima \& Fenner 2000). A common way of analysing the influence of environment heterogeneity on these younger demographic stages is to compare the suitability for the recruitment of different microhabitats with contrasting abiotic conditions (e.g. Battaglia, Fore \& Sharitz 2000; Rey \& Alcántara 2000; Gómez-Aparicio 2008). However, habitat filtering often occurs at very fine spatial scales, which demonstrates a need for the quantification of the most influential environmental factors operating at different sequential life history stages. Detailed studies explicitly measuring continuous gradients of microhabitat conditions are, therefore, essential to fully understand the optimal conditions where natural recruitment successfully occurs (concept of regeneration niche, sensu Grubb 1977) and thus to verify the existence of species habitat partitioning.

An accurate characterization of microhabitat-specific suitability for recruitment requires a 'linking-stages' approach, where plant recruitment is explored across consecutive demographic stages (seeds, seedlings, saplings) that are connected by transitional processes (dispersal, germination, emergence and survival) (Herrera et al. 1994; Clark et al. 1999). All these demographic processes are microhabitat-dependent (Schupp \& Fuentes 1995; Hulme 1997), but they are not always influenced similarly by the same microhabitat conditions (GómezAparicio 2008; Norden et al. 2009). This is particularly common in Mediterranean ecosystems, where recruitment-driving processes are frequently discordant due to different microhabitat associations through subsequent life history stages (Jordano \& Herrera 1995; Rey \& Alcántara 2000; Traveset et al. 2003). Discordant patterns of microhabitat suitability over the life cycle of the plant lead to ontogenetic conflicts since the most favourable sites for one stage may not be the most favourable for others (Schupp 1995). At the species level, a well-known demographic conflict involves the differential responses between seeds and seedlings (i.e. seed-seedling conflict), in which microhabitats with a high predation risk for seeds exhibit more favourable conditions for subsequent seedling establishment and vice versa (Houle 1992; Herrera et al. 1994; Schupp 1995; Rey \& Alcántara 2000). At the community level, ontogenetic conflicts might also occur, involving changes in species' performance rankings across demographic stages (Baraloto, Goldberg \& Bonal 2005a). In spite of their potential contribution as mechanisms of species coexistence, amongspecies rank reversals through ontogeny remain poorly understood (Clark \& Clark 1992; Baraloto, Goldberg \& Bonal 2005a), especially in Mediterranean-type ecosystems.

Recruitment-driving processes are not only influenced by microhabitat conditions but also by several intrinsic plant traits, such as seed size. Similarly to the above-discussed onto- genetic conflicts across microhabitats, opposing selective pressures among demographic stages have been described in relation to seed size due to the compromise between increasing seedling performance and reducing attraction for predators, as well as favouring successful seed dispersal (Moegenburg 1996; Alcántara \& Rey 2003; Gómez 2004). Although there may be a considerable intraspecific variability in seed size, theoretical models have predicted the evolution of an optimal propagule size based on the existence of a trade-off between offspring number and size (Smith \& Fretwell 1974). However, the occurrence of ontogenetic conflicting pressures may hinder the identification of the seed size that maximizes the overall probability of recruitment (i.e. optimal seed size). This attribute may also contribute to interspecific performance differences and thus promotes the coexistence among species differing in seed size (Kneitel \& Chase 2004; Baraloto, Forget \& Goldberg 2005b). To gain an accurate view of the selective pressures acting on seed size and the extent to which interspecific differences in this trait favour that potentially competing species do coexist, it is advisable to consider the entire life cycle of the organisms (Moles \& Westoby 2004). However, this has seldom been explored in long-lived perennial species due to the enormous costs for obtaining long-term data for different species across multiple life history stages (see Baraloto, Forget \& Goldberg 2005b).

The present study comprises an array of information on the regeneration ecology of two dominant coexisting oak species the deciduous Quercus canariensis Willd and the evergreen Quercus suber L. - that differ in several functional traits, such as seed size. In the study area, adults of both oak species segregate along environmental gradients of topography and soil moisture, forming forests with distinct canopy cover. Quercus suber tends to dominate in habitats with a lower availability of soil water and nutrients where the overstorey canopy is relatively sparse (Pérez-Ramos 2007), whereas Q. canariensis is more abundant in moister habitats with denser canopies (Urbieta, Zavala \& Marañón 2008a). At regional scale, about $60-70 \%$ of inventoried forest plots with $Q$. suber and/or Q. canariensis lacked natural regeneration (Urbieta et al. 2011).

In this paper, we used a multi-stage demographic approach aimed at characterizing the main stage-specific probabilities of recruitment (seed survival, seed germination, seedling emergence and survival during the first 3 years of life) in the two coexisting oak species along a wide and continuous gradient of plant cover (used here as a surrogate of microhabitat conditions). In addition, we investigated the implications of seed size variation, using a broad range of seed mass for the two studied oak species. We calibrated linear and nonlinear likelihood models for each of these consecutive life history stages and calculated overall probabilities of recruitment along plant cover and seed mass variation. These models were further validated through comparisons with the natural distribution of saplings at the study area. Specifically, we aimed to answer the following questions: (i) Which are the most critical demographic processes for oak recruitment?; (ii) are there ontogenetic conflicts, both within- and among-species (i.e. species rank reversals), 
along a continuous gradient of plant cover?; and (iii) are there opposing selective pressures on seed size among subsequent demographic stages?

By answering these questions, we seek to gain insights into the characterization of the regeneration niche of oak species with contrasting functional attributes, including seed size, and their relationships with distribution patterns of adults along the landscape. The identification of ontogenetic conflicts, both within- and among-species, will enable us to better understand the underlying mechanisms that promote species coexistence in Mediterranean mixed-oak forests. The information provided by this study will also contribute to develop ecologically based management and restoration strategies in Mediterranean forests.

\section{Methods}

\section{STUDY AREA}

The study was conducted in 'La Sauceda' forest (530 $\mathrm{m}$ above sea level, $36^{\circ} 31^{\prime} 54^{\prime \prime} \mathrm{N}, 5^{\circ} 34^{\prime} 29^{\prime \prime} \mathrm{W}$ ), located in the mixed-oak forests of Aljibe Mountains, near the Strait of Gibraltar, in southern Spain (see a detailed description of the experimental site in Quilchano et al. 2008 and Pérez-Ramos et al. 2008a). Climate is sub-humid Mediterranean-type, with mild and wet winters alternating with hot and dry summers. Annual mean temperature ranges from 14.6 to $18.4{ }^{\circ} \mathrm{C}$ (mean of $17{ }^{\circ} \mathrm{C}$ ). Annual mean rainfall varies from 900 to 1800 (mean of $1265 \mathrm{~mm}$ ), with the heaviest rainfall occurring in autumn, winter and spring, followed by dry summers. Bedrock is predominately Oligo-Miocene sandstone, which produces acidic, sandy and nutrientpoor soils, although frequently there are interspersed layers of marl sediments, yielding soils richer in clay. Vegetation is dominated by evergreen cork oak $(Q$. suber) forests, mixed with winter-deciduous oaks ( $Q$. canariensis), which are more abundant near streams (Urbieta, Zavala \& Marañón 2008a). The shrubby understorey is diverse and rich in endemic taxa (Ojeda, Marañón \& Arroyo 2000). Most of the forested area was protected in 1989 as 'Los Alcornocales' (meaning 'cork oak forests') Natural Park, covering about $1680 \mathrm{~km}^{2}$.

\section{SAMPLING DESIGN AND DATA COLLECTION}

Acorns of $Q$. suber and $Q$. canariensis were collected in the surroundings of the experimental site from several trees (at least 10 of each species) to encompass intraspecific variation. We selected healthy acorns, discarding those infected by moth or beetle larvae through flotation (Gribko \& Jones 1995). Selected acorns were stored on a moist substrate at $2-4{ }^{\circ} \mathrm{C}$ until used in the experiments and individually weighed to the nearest $0.01 \mathrm{~g}$. Mean $\pm \mathrm{SD}$ (standard deviation) acorn fresh weight was: $5.96 \pm 2.20 \mathrm{~g}$ for $Q$. suber (range of 2.31$17.27 \mathrm{~g}$ ) and $2.57 \pm 1.03 \mathrm{~g}$ for $Q$. canariensis (range of $0.91-8.29 \mathrm{~g}$ ). We used acorn fresh weight as a surrogate of dry seed mass, justified by their high correlation (Quero et al. 2007). Acorns of known weight were further distributed in experimental units (see subsections below on 'Seed survival' and 'Seedling monitoring') on the forest floor along a wide and continuous gradient of plant cover, from open spaces [up to $90 \%$ full sun and leaf area index (LAI) of 0.35 ] to shady microhabitats under shrubs and trees (down to $10 \%$ full sun, $4.00 \mathrm{LAI}$ ).

Plant cover was estimated by means of hemispherical photographs taken in the centre of each experimental unit, using a horizontally levelled digital camera with fish-eye lens of $180^{\circ}$ field of view (Quilc- hano et al. 2008). Digital images were analysed with specific software (Hemiview Canopy Analysis; Delta-T Devices Ltd., 1999, v. 2.1). We selected plant cover (LAI) as the most representative variable of microhabitat conditions based on previous studies carried out at the same mixed-oak forests which aimed to identify the main abiotic factors affecting each stage-specific probability of recruitment (GómezAparicio et al. 2008; Pérez-Ramos et al. 2008b; Urbieta et al. 2008b). In this study, we used a multi-stage demographic approach to explore the existence of within- and among-species differences during plant ontogeny along a broad range of microhabitats differing in plant cover. Specifically, we selected LAI because: (i) it was the environmental variable mostly affecting seed predation (Pérez-Ramos et al. 2008b); and (ii) it was significantly correlated with light and maximum soil water content, which are the most influential factors for seedling emergence and survival (Gómez-Aparicio et al. 2008; Urbieta et al. 2008b). Thus, plant cover was negatively correlated with the global site factor (GSF; $r=-0.91, P<0.001$ ) as well as with the soil volumetric water content reached during the rainy season $(r=-0.39, P<0.005)$. Open areas tended to suffer events of sporadic soil waterlogging during the wet period due to less interception of rain by canopy and, in most cases, a higher proportion of clay (Urbieta et al. 2008b).

\section{Seed survival}

The probability of seed survival (i.e. non-removed acorns) was evaluated by individually monitoring a total of 576 acorns (including both species) randomly distributed across 144 experimental units. In each unit, four acorns of a single species were placed on the ground, in the corners of a $0.5-\mathrm{m}^{2}$ quadrat. Units were periodically visited and acorns individually monitored until there was no longer any evidence of seed removal (see Pérez-Ramos et al. 2008b for further details). This experiment was repeated during two consecutive reproductive cycles (2003/04 and 2004/05), which showed contrasting differences in seed production and, thereby, in food availability for seed consumers. Thus, the estimated seed production in $Q$. canariensis varied from $344 \mathrm{~g} \mathrm{~m}^{-2}$ (2003/04 cycle) to $58 \mathrm{~g} \mathrm{~m}^{-2}$ (2004/05 cycle) in the study area, whereas it remained low during both years (below $14 \mathrm{~g} \mathrm{~m}^{-2}$ ) in the case of $Q$. suber (Pérez-Ramos 2007).

Although it is likely that a small fraction of removed acorns escape consumption, in which case the animals responsible act as secondary seed dispersers (e.g. Pérez-Ramos et al. 2007; Pons \& Pausas 2007; Purves et al. 2007; Gómez-Aparicio et al. 2008), a recent study on acorn dispersal in the study area has shown that most of them are completely eaten, mainly by rodents (I. M. Pérez-Ramos, J. R. Verdú, C. Numa \& J. M. Lobo, unpublished data). Thus, from a quantitative perspective, we assumed that the seeds recorded in this study as 'removed' could be considered as 'losses' for recruitment. Therefore, 'seed removal' has been considered as a surrogate of 'seed predation' in this study.

\section{Seedling monitoring}

The processes of seed germination, seedling emergence and survival, and seedling growth were studied by conducting a seed sowing experiment at the same study site where seed removal was evaluated. In December 2003, a total of 600 acorns of each species were randomly placed across 60 experimental units distributed along the abovedescribed gradient of plant cover. Ten acorns per species were sown in each unit at 1-3 cm depth, simulating biotic seed dispersal and burial by European jays (Kollmann \& Schill 1996), rodents (Gómez, Puerta-Piñero \& Schupp 2008) or dung beetles (Pérez-Ramos et al. 
2007). All the experimental units were protected by wire cages $(25 \times 25 \times 25 \mathrm{~cm}, 1.3 \mathrm{~cm}$ mesh size $)$ to exclude seed predators. Seed germination was assessed after the first summer, unearthing non-emerged seeds and inspecting the presence of radicles. Seedling emergence and survival were monitored periodically from February 2004 to February 2007. Censuses were carried out bi-weekly during the first year and every 6 months (in late winter and after summer, coinciding with the peaks of maximum seedling mortality) during the two remaining years (see Urbieta et al. $2008 \mathrm{~b}$ for further details).

For measurements of seedling growth, we selected one individual per species and available experimental unit. For each selected seedling, non-destructive measurements in stems and leaves were taken repeatedly during two consecutive growing seasons (2004 and 2005). Above-ground biomass for each year was estimated from these nondestructive measurements using linear regressions calculated in additional harvested seedlings (see details in Pérez-Ramos et al. 2010).

\section{Abundance and natural distribution of saplings}

To assess whether the natural sapling distribution of the two studied species mirrored the net results predicted by our models (i.e. model validation), a static survey of sapling abundance was conducted at the study area in autumn 2004. The number of saplings (i.e. individuals more than 2 years old) was counted in six randomly positioned transects $(25 \times 2 \mathrm{~m})$, and the microhabitat in which they had established was also recorded. We categorized three types of microhabitats as a function of their predominant plant cover: dense shrub (inside shrub and tree overstorey, with LAI values ranging from 2 to 3.5), under tree (beneath tree canopy, without shrub understorey; LAI from 1.3 to 2 ) and open microsites (without the protection of shrub and tree canopy; LAI from 0.3 to 1.3 ). In addition, we estimated the natural availability of each microhabitat type at the study area by visually estimating the percentage covered by each of the three microhabitat types along the transects.

\section{DATA ANALYSES}

\section{Among-species ontogenetic rank reversals}

Interspecific differences for each of the stage-specific probabilities of recruitment were tested to explore the existence of among-species ontogenetic rank reversals. We used Generalized Linear Models assuming a logit relationship between the dependent (treated as a binomial variable) and the independent variable (the oak species). These analyses were carried out using STAтistica (v. 6; StatSoft Inc., 2001).

\section{Recruitment models along plant cover and seed mass variation}

The stage-specific probability of recruitment was modelled independently for each of the life history stages considered in this study (seed survival, seed germination, seedling emergence and seedling survival during the first 3 years of life) as a function of plant cover and seed mass. The overall probability of recruitment was further calculated as the product of all these six stage-specific probabilities. In addition, we used the same modelling approach to fit models of seedling growth (particularly for 1- and 2-yearold seedling above-ground biomass) along the explored range of plant cover and seed mass. All models were fitted individually for each oak species, using maximum likelihood techniques (Edwards 1992) with simulated annealing (Goffe, Ferrier \& Rogers 1994).
We tested five alternative functions (linear, exponential, Michaelis-Menten, logistic and power), which cover a wide range of possible responses. We first tested models for each predictor and function independently, and the best of the five models was then compared to the null model, which assumes no effect of any factor. Second, to test for interactions between both factors, we fitted bivariate models in which the second predictor (i.e. seed mass) was added either additively or multiplicatively. Competing models were compared with the Akaike's Information Criterion corrected for small sample sizes $\left(\mathrm{AIC}_{\mathrm{c}}\right.$ ) (Burnham \& Anderson 2002) as a measure of goodness of fit: the lower the $\mathrm{AIC}_{\mathrm{c}}$ value, the better the model. The absolute magnitude of the differences in $\mathrm{AIC}_{\mathrm{c}}(\triangle \mathrm{AIC})$ between alternative models provided an objective measure of the strength of empirical support for each one of them (Akaike 1992). Models with $\triangle \mathrm{AIC}$ between 0 and 2 were considered to have equivalent and substantial empirical support (Burnham \& Anderson 2002).

For the seed stage, we combined maximum likelihood methods and survival time analysis to parameterize seed survival models as a function of plant cover and seed mass, considering not only the final 'fate' of each seed (i.e. survived or not) but also the time each seed remained non-removed (see Pérez-Ramos et al. 2008b for more details). The processes of seed germination, seedling emergence and survival were described by a binomial distribution, whereas seedling growth data were fitted to a normal distribution (see Urbieta et al. 2008b; and Pérez-Ramos et al. 2010 for more details). To test interspecific differences along the explored range of plant cover and seed mass, we calibrated a general model that was fitted to all the data (saturated model, without distinguishing between the species) for each of the life history stages considered in this study. The $\mathrm{AIC}_{\mathrm{c}}$ of each saturated model was compared with the sum of $\mathrm{AIC}_{\mathrm{c}}$ of their two corresponding species-specific models; only when $\Delta \mathrm{AIC}_{\mathrm{c}}>2$, differences between species were considered to be significant. Seed survival models were implemented in programs written in $\mathrm{C}$ (Borland $\mathrm{C}+$; Borland International Inc., 1996, version 5.01). The remaining models were implemented using the likelihood package R.1.1, and software written specifically for this study in R.2.5.0 (R Development Core Team, 2006).

\section{Abundance and natural distribution of saplings}

To assess whether natural saplings of both species were randomly distributed along the landscape and thus validate our overall-recruitment models, we conducted a Chi-square test to compare the observed frequencies of saplings among the three above-described types of microhabitats versus those expected by chance (i.e. the proportion of available microhabitats at the study site). This analysis was carried out using STATISTICA (v. 6; StatSoft Inc., 2001).

\section{Results}

\section{CRITICAL DEMOGRAPHIC PROCESSES AND AMONG- SPECIES ONTOGENETIC RANK REVERSALS}

We detected strong differences in the stage-specific probabilities of recruitment through ontogeny. In both oak species, the most critical demographic process occurred during the seedseedling transition, with mean probabilities of seed survival below 0.4 (Fig. 1). The relative importance of this stage for overall recruitment was more marked in the 2004/05 cycle 
Fig. 1. Stage-specific probabilities of recruitment from a dispersed seed to an established 3 -year-old seedling, in the two studied oak species (Quercus canariensis is represented with black symbols and solid lines, whereas Quercus suber with white symbols and dotted lines). Seed survival was monitored during two consecutive reproductive cycles (2003/04 and 2004/05, represented with circles and triangles, respectively), with very contrasting initial seed supply. Significant interspecific differences for each of the life history stages considered in this study are indicated as follows: $* P<0.05$; $* * P<0.01 ; * * * P<0.001$; ns, not significant.

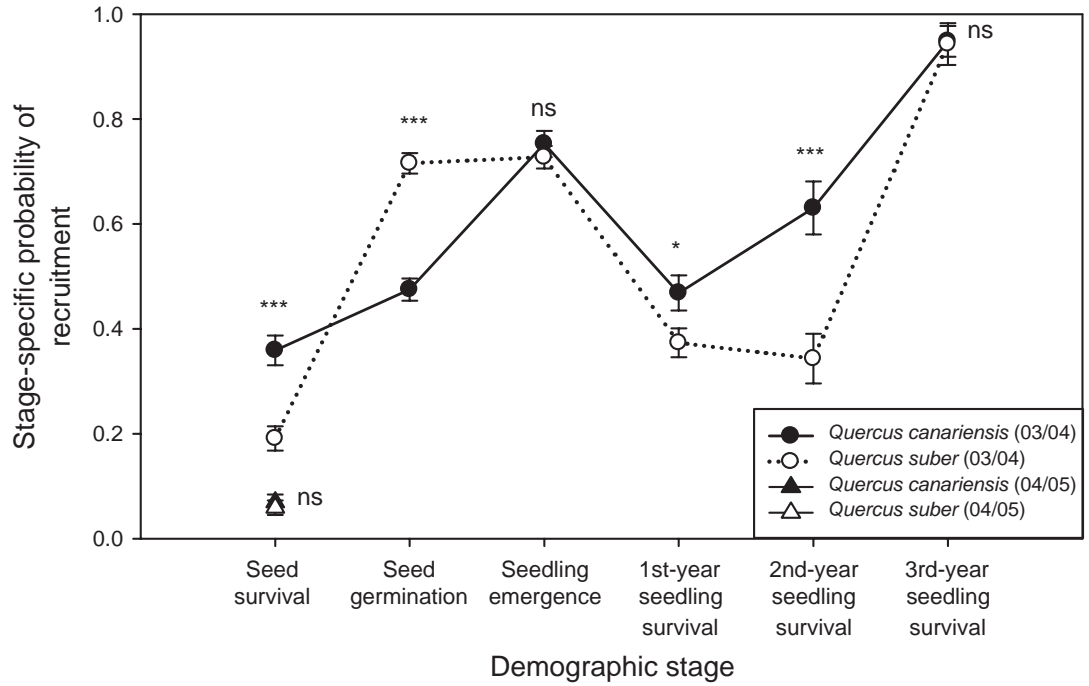

LAI on germination and seedling emergence in $Q$. suber, as indicated by the strongest empirical support of the bivariate models including both predictors (Appendix S1). In addition, seedling survival during the third year decreased logistically with increasing plant cover, but only for $Q$. suber (Appendix S1 and Fig. 2b).

Regarding interspecific differences, $Q$. canariensis showed a higher probability of seed survival but a lower probability of seed germination compared with $Q$. suber, as indicated by the higher empirical support of the species-specific models in comparison with their respective saturated models $\left(\Delta \mathrm{AIC}_{\mathrm{c}}=63.15\right.$ and 55.72 for seed survival and seed germination, respectively).

\section{CONFLICTING SELECTIVE PRESSURES ON SEED SIZE}

\section{AMONG DEMOGRAPHIC STAGES}

Opposite tendencies were found for $Q$. suber between the seed and the seedling stages along the explored range of seed mass. Thus, the processes of seed germination and seedling survival during the first year were correlated positively with seed mass, whereas seed survival was negatively correlated with this trait (Fig. 2d and Appendix S1). In Q. canariensis, seed survival also decreased linearly with increasing seed mass, but the rest of transitional processes were not significantly influenced by this trait (Fig. 2c and Appendix S1).

\section{OVERALL-RECRUITMENT TRENDS}

The results of this study provide some evidence of regeneration niche partitioning when comparing the overall-recruitment probabilities between the two studied oak species. The cumulative probabilities of recruitment were very low in both oak species (below 5\%), especially during the low-production cycle (2004/05).

Although both species showed the lowest probabilities of recruitment at the high end of the LAI gradient (i.e. the most shaded microsites), they showed differences in recruitment at 

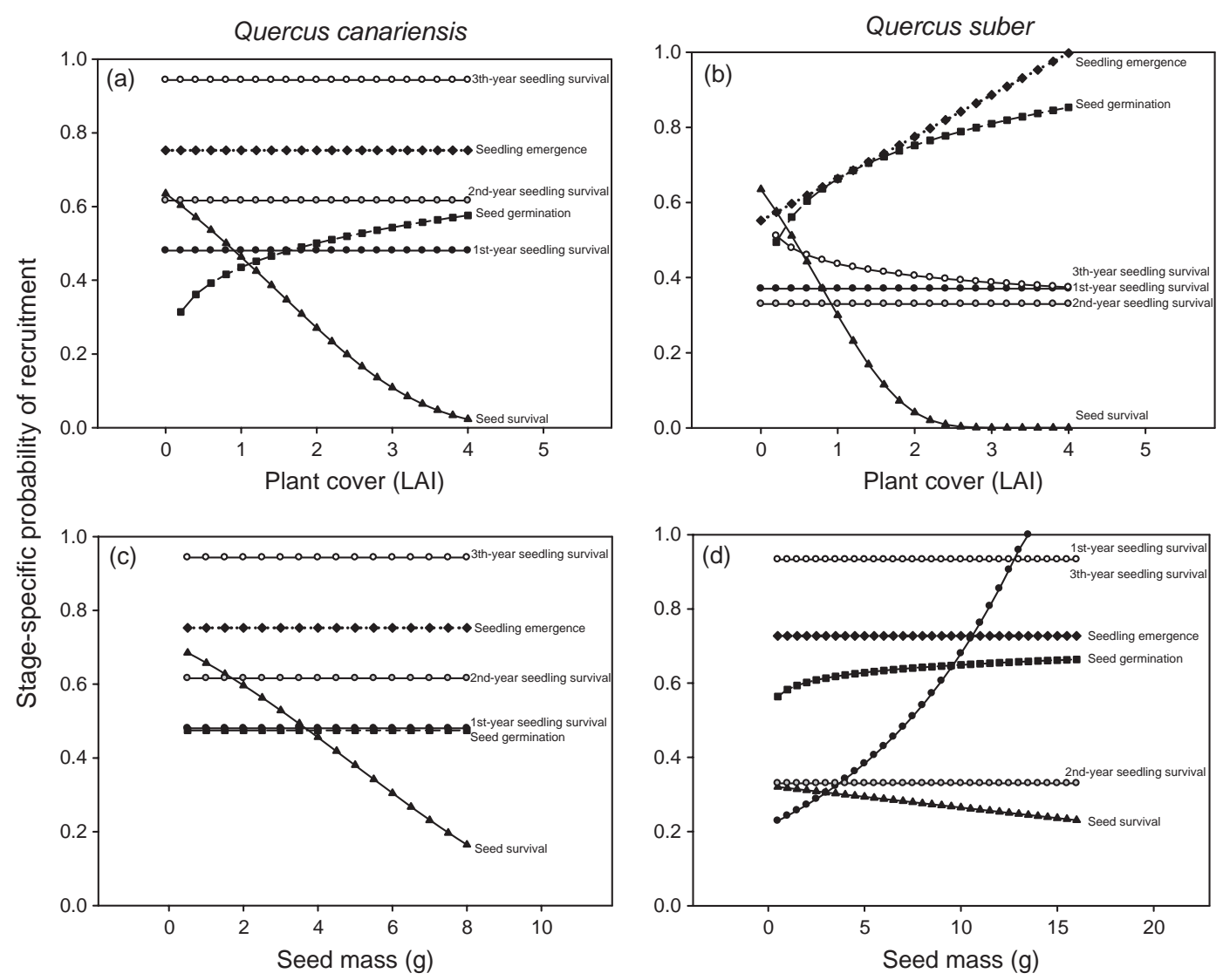

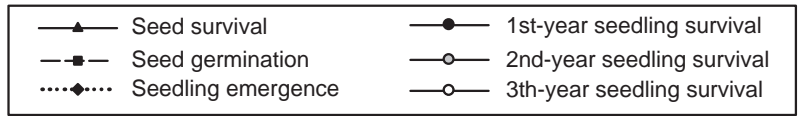

Fig. 2. Within-species ontogenetic conflicts along plant cover (a and b; LAI = leaf area index) and seed mass variation (c and d) for the two oak species. Seed survival data correspond to the 2003/04 reproductive cycle. Straight horizontal lines denote no effect of plant cover or seed mass on the stage-specific probabilities of recruitment, but they are included for comparative purposes.

low and intermediate LAI values. In $Q$. canariensis, the overall-recruitment probability slightly decreased as LAI approached zero, and peak recruitment appeared to occur in microhabitats with low-intermediate values of plant cover (LAI $\sim 1$; Fig. 3a). Interestingly, this recruitment peak was displaced towards the low end of the LAI gradient during the low-production cycle (2004/05; Fig. 3b). In comparison, $Q$. suber had the highest probabilities of cumulative recruitment in the most open microhabitats during the two sampling periods (Fig. 3a,b). Quercus canariensis outperformed its co-dominant oak species along most of the LAI gradient, but these interspecific differences disappeared in shady microhabitats (Fig. 3a,b).

Regarding seedling growth, the above-ground biomass (after two growing seasons) also decreased along the plant cover gradient in $Q$. suber, but no effect of LAI was detected for $Q$. canariensis (Appendix S1 and Fig. 3f).

The seed mass that maximized the overall probability of recruitment (i.e. optimal seed size) differed substantially between the two oak species, smaller seeds being favoured in Q. canariensis, whereas acorns of large (in 2003/04 cycle) or intermediate size (in 2004/05 cycle) were favoured in Q. suber (Fig. 3c,d). First-year above-ground biomass increased with seed mass in both oak species (Appendix S1 and Fig. 3e), resulting in a trade-off for $Q$. canariensis when compared to the variation of its overall-recruitment probability.

\section{ABUNDANCE AND NATURAL DISTRIBUTION OF \\ SAPLINGS}

The natural distribution of $Q$. canariensis saplings in the three types of microhabitats was not random, compared with the availability of each of them in the study area $\left(\chi^{2}=49.52 ; P<0.001\right)$. The observed density of $Q$. canariensis saplings was lower than that expected by chance in the two extremes of the LAI gradient (i.e. both in open and dense microhabitats; Fig. 4). However, the observed distribution pattern of $Q$. suber saplings did not statistically differ from those expected by chance $\left(\chi^{2}=2.64\right.$; $P=0.27)$, likely due to the low densities of saplings quantified at the study area for this species (Fig. 4). 

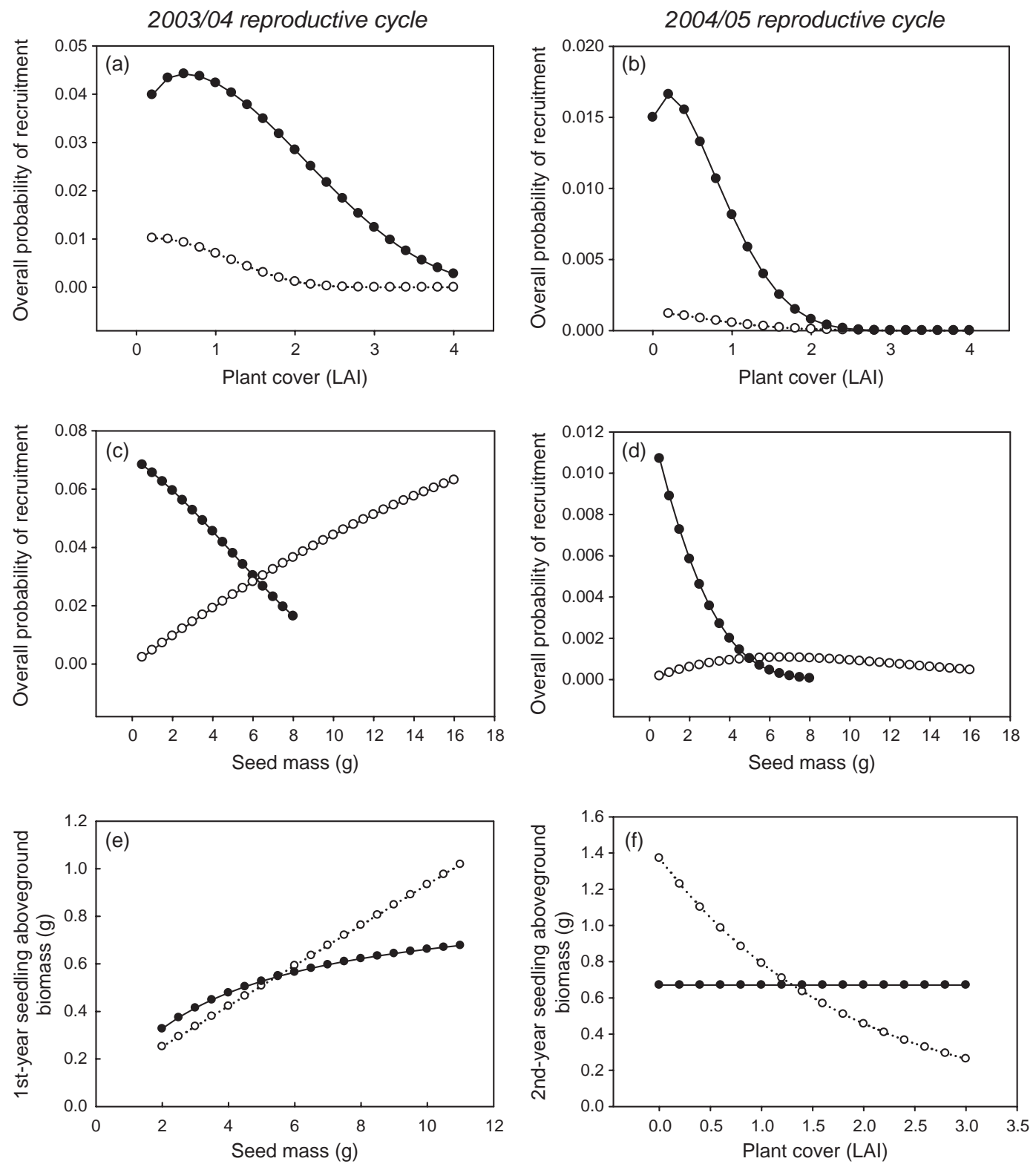

Fig. 3. Predicted variation in the overall probability of recruitment (a-d) and seedling above-ground biomass (e and f) along plant cover $($ LAI $=$ leaf area index) and seed mass variation. The overall probability of recruitment was calculated as the product of all stage-specific probabilities from a dispersed seed to an established seedling of 3 years old. Quercus canariensis is represented with black symbols and solid lines, whereas Quercus suber with white symbols and dotted lines.

\section{Discussion}

\section{CRITICAL DEMOGRAPHIC PROCESSES AND AMONG- SPECIES ONTOGENETIC RANK REVERSALS}

The two studied oak species were strongly recruitment-limited in spite of their high co-dominance as adults in the forest canopy. Previous studies suggested that the regeneration process of these two species is more limited by safe sites than by seed availability (I. M. Pérez-Ramos \& T. Marañón, unpublished data), a common feature in recruitment-limited species of Mediterranean forests (Gómez-Aparicio 2008; Mendoza et al. 2009). In contrast, a comparative study of two coexisting oak species in NE Spain showed that predispersal predation and seed supply were the most critical processes, whereas no interspecific differences were observed either in post-dispersal predation or in seedling establishment (Espelta et al. 2009).

In our study, the most critical demographic process occurred during the seed-seedling transition, which has been identified as an important bottleneck in the regeneration of other Mediterranean oak species (Herrera 1995; Santos \& Tellería 1997; Pulido \& Díaz 2005; Pausas et al. 2009). Acorns are usually subjected to intensive predation pressure due to their large size and their high nutritional content, constituting an important part of the diet of many animals (e.g. Gómez, García \& Zamora 2003; Pérez-Ramos \& Marañón 2008). 


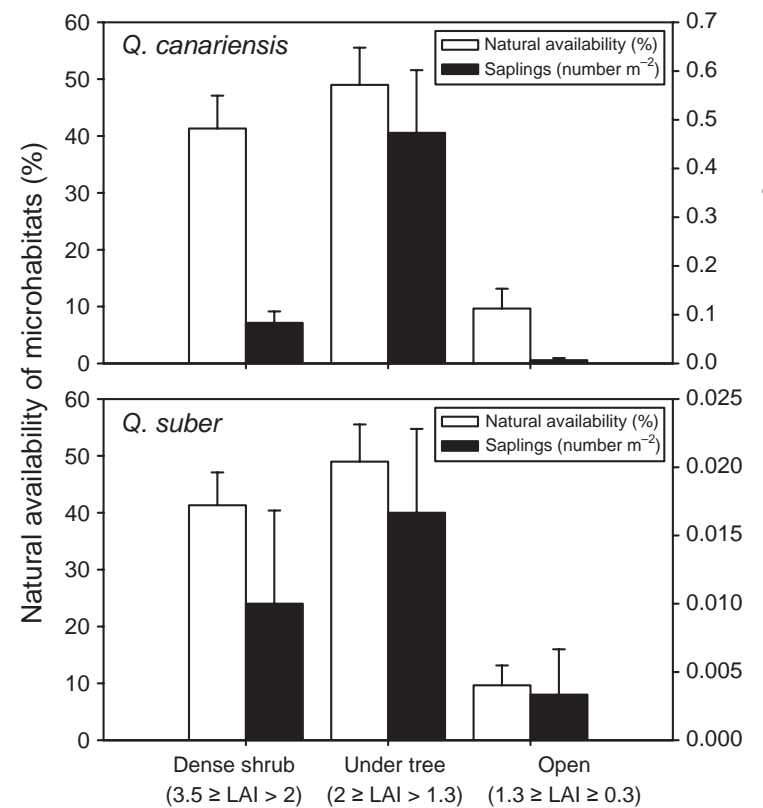

Type of microhabitat

Fig. 4. Comparison between the natural availability of the three main types of microhabitats (dense shrub, under tree and open; LAI = leaf area index) and the density of saplings found in each of them at the study site for the two oak species (Quercus canariensis and Quercus suber). White bars represent the mean proportion cover of each microhabitat type. Vertical bars denote standard error values. Note that the represented scale of the right $Y$-axis is different for each of the two studied oak species.

As expected, the probability of seed survival substantially decreased in the reproductive cycle where the estimated seed production - and consequently the resource availability for seed consumers - was lower, supporting the predator-satiation hypothesis (Janzen 1970; Silvertown 1980).

Seedling survival during the first 2 years was the most limiting process at the seedling stage. Since most seedlings died during the dry summer season, the main cause of mortality may be attributable to the water stress experienced during this period, as has been reported by other studies in Mediterranean ecosystems (Lloret, Casanovas \& Peñuelas 1999; Rey \& Alcántara 2000; Castro et al. 2005; Pulido \& Díaz 2005).

Species ranking diverged substantially through the life history stages considered in this study due to different ontogenetic trends among species. Quercus canariensis outperformed its coexisting oak species during the processes of seed and seedling survival, but this reversed during seed germination. These interspecific differences in seed germination seem to be an intrinsic characteristic of the two studied species, as demonstrated in a parallel study under controlled conditions (PérezRamos \& Marañón 2009). Quercus canariensis acorns were removed slowly and at lower proportion than those of $Q$. suber, likely due to its generally smaller seed size (Pérez-Ramos et al. 2008b). Afterwards, seedlings of the deciduous species emerged earlier, allowing them to benefit from growing season resources for a longer period of time (Urbieta et al. 2008b). A shortened time to emergence likely enabled seedlings to develop more extensive root systems, thus enhancing their probability of survival during the dry period (Seiwa 2000; Verdú \& Traveset 2005; Castro 2006). As a consequence of these among-species discordances, our overall-recruitment models predicted that $Q$. suber was more recruitment-limited than $Q$. canariensis, a fact that was supported by the lower density of saplings detected for this species at the study area. As predicted by theory (MacArthur \& Levins 1964; Chesson 2000), shifts in species' performance rankings between different situations constitute a necessary, but not always sufficient, condition for species coexistence. Our findings suggest that amongspecies rank reversals through ontogeny could contribute to regeneration niche partitioning in the two co-occurring oak species, as will be discussed further on.

WITHIN-SPECIES ONTOGENETIC CONFLICTS ALONG A PLANT COVER GRADIENT

A highly significant contribution of this study is the demonstration of within-species ontogenetic conflicts along a wide and continuous gradient of plant cover. Recruitment-driving processes during the seed and the seedling stages showed opposing tendencies along the plant cover gradient. Seed survival severely decreased with increasing plant cover, which could be attributed to the higher foraging activity of rodents in more closed microhabitats where they find more protection against their own predators (Herrera 1995; Hulme \& Hunt 1999; Gómez, García \& Zamora 2003; Pons \& Pausas 2007; Pérez-Ramos et al. 2008b). In contrast, seed germination and seedling emergence were reduced in more open microhabitats owing to the unfavourable environmental conditions generated by events of temporal waterlogging that are more frequent in this type of microsite that often have clayey soils (Urbieta et al. 2008b). The negative effects of waterlogging are related to the fact that seedlings may have experienced low oxygen concentration, potentially curtailing respiration and delaying root and shoot development before the onset of the dry period (Urbieta et al. 2008b). Similar uncouplings between seed and seedling stages have been previously documented in other studies that compared the suitability of different microhabitats with contrasting abiotic conditions (e.g. Houle 1994, 1998; Schupp 1995; Rey \& Alcántara 2000). To our knowledge, the present study is the first that describes seed-seedling conflicts at very fine spatial scale across the exploration of a continuous gradient of microhabitat conditions.

Interestingly, another ontogenetic conflict was detected within the seedling stage in the case of $Q$. suber. Specifically, the higher success of shaded microhabitats for initial recruitment was reversed in 3-year-old seedlings. The net carbon balance for this species probably became negative under limiting light conditions, when seed reserves were depleted and seedlings were more dependent on external resources (Pérez-Ramos et al. 2010). The absence of a negative response to light scarcity in the deciduous species supports previous studies identifying these species as highly shade-tolerant during early life history stages (Gómez-Aparicio, Valladares \& Zamora 2006; Quero et al. 2006). 
Most studies on ontogenetic niche shifts have only compared two life history stages (but see Jordano \& Herrera 1995; Quero et al. 2008), such as seedlings and mature trees (Cavender-Bares \& Bazzaz 2000) or juveniles of different ages (Espelta, Riba \& Retana 1995). However, our multi-stage demographic approach has enabled us to identify several ontogenetic conflicts among subsequent demographic stages along a natural gradient of microhabitat conditions.

CONFLICTING SELECTIVE PRESSURES ON SEED SIZE AMONG DEMOGRAPHIC STAGES: IS THERE AN

OPTIMAL SEED SIZE?

Conflicting selective pressures on seed mass through ontogeny have been found to be more complex than previously proposed (Eriksson \& Jakobsson 1999) and can occur at different stages, from a dispersed seed to an established seedling. Larger seed size exercised a positive effect on different processes within the seedling stage, but reduced the probability to escape from predation during the seed stage, as reported for Quercus ilex in other Mediterranean forests (Gómez 2004). A possible advantage of larger seeds is that they could germinate above deeper leaf litter (Molofsky \& Augspurger 1992). In addition, larger seeds produced larger seedlings, which are able to gain more access to limited resources with steep vertical gradients such as light or soil moisture (Leishman \& Westoby 1994; Metcalfe \& Grubb 1995). The advantages of large acorns on the seedling stage disappeared after the second year, consistent with previous studies demonstrating that effects of seed size decline over time (Castro 1999; Baraloto, Forget \& Goldberg 2005b; Poorter \& Rose 2005).

The consequences of seed size for population dynamics will depend on the probability of different microhabitats to receive seeds of larger or smaller size. It would be interesting to investigate how seed size modulates seed dispersal patterns by different animals and species-specific seed 'fate' through the mosaic of different microhabitats found in these forests (see example for a bird-dispersed plant in Alcántara et al. 2000).

The existence of opposing selective pressures on seed mass and their differential influence on the two studied oak species might support the occurrence of species-specific optimal seed sizes. In the case of $Q$. canariensis, our overall-recruitment models predicted that small-sized seeds were favoured against the larger ones due to their lower probability of predation as well as the absence of an effect of this trait on the subsequent life history stages. Nevertheless, the small fraction of large seeds escaping from predation produced larger seedlings, resulting in a trade-off among different fitness components (sensu Baraloto, Goldberg \& Bonal 2005a). In Q. suber, however, the peak of maximum recruitment was predicted for seeds of large or intermediate size, depending on the natural resource availability for seed predators. Thus, in a low-production cycle, the positive effects of larger seeds on the seedling stage were partially altered by their opposite negative effects on seed survival, displacing the peak of maximum recruitment towards intermediate values of seed size. The species-specific optimal seed sizes predicted by our modelling approach may explain why the natural phenotypic selection has favoured that $Q$. canariensis produces smaller-sized acorns compared with its co-occurring oak species at the studied forest sites.

\section{REGENERATION NICHE AND OAK SPECIES COEXISTENCE}

The exploration of a wide gradient of plant cover allowed us to determine a high variation among microhabitats in their specific suitability for overall recruitment, as a result of different selective forces operating at different stages of the regeneration cycle. In both oak species, the negative effects of denser plant cover on the seed stage were not counteracted by the positive effects exercised on the subsequent demographic processes occurring over the seedling stage. Since seed predation was the most limiting process, safe sites for recruitment could be defined as those where seeds showed a lower predation probability. As a consequence, the overall probability of recruitment strongly decreased as plant cover increased in both oak species. However, the less pronounced effect of this process on $Q$. $c a$ nariensis acorns generated a peak of maximum recruitment at low-intermediate values of plant cover. Interestingly, this recruitment peak was displaced towards the lower end of the LAI gradient during a low-production cycle, where the lower abundance of resources decreased the probability of a seed to escape from predators and establish as a seedling (Kelly 1994; Kelly \& Sork 2002; Pérez-Ramos \& Marañón 2008). The spatial patterns predicted by our overall-recruitment models were validated with the static survey of sapling abundance conducted at the study area, which showed that microhabitats located under trees harboured the highest densities of saplings (particularly of $Q$. canariensis).

Overall, our modelling approach provides some evidence for regeneration niche partitioning between the two co-occurring oak species, in turn, influencing their distribution patterns as saplings and adults at the study area. These results are consistent with the tendencies reported by previous studies proposing deciduous species to be more frequent in habitats with denser canopy, where water and nutrient availabilities are usually higher (Aerts 1995; Maltez-Mouro, García \& Freitas 2009). The differential species responses to microhabitat conditions detected in our study at early life stages support the role of regeneration niche partitioning as potential driver of species coexistence and tree community structure in Mediterranean forests (Grubb 1977; Silvertown 2004). Ontogenetic conflicts and among-species rank reversals in recruitment lead to spatially discordant patterns of regeneration among microhabitats with different plant cover as well as between coexisting species differing in seed size. We conclude that within- and among-species differences through plant ontogeny, arising from differential response patterns to microhabitat heterogeneity and seed size variation, could be of great importance for oak species niche segregation, driving stand dynamics and species spatial distribution in the landscape. The information provided 
here about the most favourable conditions and traits for recruitment in the two oak species, with known regeneration impairments, could be applied to improve ecologically based management and restoration strategies in Mediterranean forests.

\section{Acknowledgements}

We thank the Consejería de Medio Ambiente (Andalusian Government) and Felipe Oliveros, then Director of Los Alcornocales Natural Park, for the facilities and support to carry out our fieldwork. We are very grateful to Luis V. García, Maite Domínguez, Carmen Navarro and Rocío Sánchez for field assistance, and to Robert Jones and Pedro Rey for their comments on the earlier version of the manuscript. This study was supported by a JAE-doc - contract to IMPR, by the Spanish MEC projects Heteromed (REN2002-4041-C02-02), Dinamed (CGL2005-5830-C03-01) and Interbos (CGL2008-04503-C03-01), the Andalusian PE2010-RNM-5782 project, and by European FEDER funds. This research is part of the Globimed (http:// www.globimed.net) network in forest ecology.

\section{References}

Aerts, R. (1995) The advantages of being evergreen. Trends in Ecology and Evolution, 10, 402-407.

Akaike, H. (1992) Information theory and an extension of the maximum likelihood principle. Breakthroughs in Statistics, Vol. 1 (eds S. Kotz \& N. Johnson), pp. 610-624. Springer-Verlag, London.

Alcántara, J.M., Rey, P.J., Valera, F. \& Sánchez-Lafuente, A.M. (2000) Factors shaping the seedfall pattern of a bird-dispersed plant. Ecology, 81, 19371950.

Alcántara, J.M. \& Rey, P.J. (2003) Conflicting selection pressures on seed size: evolutionary ecology of fruit size in a bird-dispersed tree, Olea europaea. Journal of Evolutionary Biology, 16, 1168-1176.

Baraloto, C., Forget, P.M. \& Goldberg, D.E. (2005b) Seed mass, seedling size and neotropical tree seedling establishment. Journal of Ecology, 93, 11561166.

Baraloto, C., Goldberg, D.E. \& Bonal, D. (2005a) Performance trade-offs among tropical tree seedlings in contrasting microhabitats. Ecology, 86, 2461-2472.

Battaglia, L.L., Foré, S.A. \& Sharitz, R.R. (2000) Seedling emergence, survival and size in relation to light and water availability in two bottomland hardwood species. Journal of Ecology, 88, 1041-1050.

Borland International Inc. (1996) Borland $C++v .5 .01$. USA.

Burnham, K.P. \& Anderson, D.R. (2002) Model Selection and Multimodel Inference: A Practical Information-Theoretic Approach, 2nd edn. Springer, Berlin, Germany.

Castro, J. (1999) Seed mass versus seedling performance in Scots pine: a maternally dependent trait. New Phytologist, 144, 153-161.

Castro, J. (2006) Short delay in timing of emergence determines establishment success in Pinus sylvestris across microhabitats. Annals of Botany, 98, 12331240.

Castro, J., Zamora, R., Hódar, J.A. \& Gómez, J.M. (2005) Alleviation of summer boosts establishment success of Pinus sylvestris in a Mediterranean mountain: an experimental approach. Plant Ecology, 181, 191-202.

Cavender-Bares, J. \& Bazzaz, F.A. (2000) Changes in drought response strategies with ontogeny in Quercus rubra: implications for scaling from seedlings to mature trees. Oecologia, 124, 8-18.

Chesson, P.L. (2000) Mechanisms of maintenance of species diversity. Annual Review of Ecology and Systematics, 31, 343-366.

Clark, D.A. \& Clark, D.B. (1992) Life history diversity of canopy and emergent trees in a neotropical rain forest. Ecological Monographs, 62, 315-344.

Clark, J.S., Beckage, B., Camill, P., Cleveland, B., Hille Ris Lambers, J., Lichter, J., Mclachlan, J., Mohan, J. \& Wyckoff, P. (1999) Interpreting recruitment limitation in forests. American Journal of Botany, 86, 1-16.

Delta-T Devices Ltd (1999) Hemiview Canopy Analysis Software version 2.1. Delta-T Devices Ltd, Cambridge, UK.

Edwards, A.W.F. (1992) Likelihood - Expanded edition. Johns Hopkins University Press, Baltimore, USA.

Eriksson, O. \& Jakobsson, A. (1999) Recruitment trade-offs and the evolution of dispersal mechanisms in plants. Evolutionary Ecology, 13, 411-423.
Espelta, J.M., Riba, M. \& Retana, J. (1995) Patterns of seedling recruitment in West-Mediterranean Quercus ilex forests influenced by canopy development. Journal of Vegetation Science, 6, 465-472.

Espelta, J.M., Cortés, P., Molowny-Horas, R. \& Retana, J. (2009) Acorn crop size and pre-dispersal predation determine inter-specific differences in the recruitment of co-occurring oaks. Oecologia, 161, 559-568.

Goffe, W.L., Ferrier, G.D. \& Rogers, J. (1994) Global optimization of statistical functions with simulated annealing. Journal of Econometrics, 60, 65-99.

Gómez, J.M. (2004) Bigger is not always better: conflicting selective pressures on seed size in Quercus ilex. Evolution, 58, 71-80.

Gómez, J.M., García, D. \& Zamora, R. (2003) Impact of vertebrate acorn- and seedling-predators on a Mediterranean Quercus pyrenaica forest. Forest Ecology and Management, 180, 125-134.

Gómez, J.M., Puerta-Piñero, C. \& Schupp, E.W. (2008) Effectiveness of rodents as local seed dispersers of Holm Oaks. Oecologia, 155, 529-537.

Gómez-Aparicio, L. (2008) Spatial patterns of recruitment in Mediterranean plant species: linking the fate of seeds, seedlings and saplings in heterogeneous landscapes at different scales. Journal of Ecology, 96, $1128-1140$.

Gómez-Aparicio, L., Valladares, F. \& Zamora, R. (2006) Differential light responses of Mediterranean tree saplings: linking ecophysiology with regeneration niche in four co-occurring species. Tree Physiology, 26, 947958.

Gómez-Aparicio, L., Pérez-Ramos, I.M., Mendoza, I., Matías, L., Quero, J.L., Castro, J., Zamora, R. \& Marañón, T. (2008) Oak seedling survival and growth along resource gradients in Mediterranean forests: implications for regeneration in current and future environmental scenarios. Oikos, 117, 1683-1699.

Gribko, L.S. \& Jones, W.E. (1995) Test of float method of assessing northern red oak acorn condition. Tree Planter's Notes, 46, 143-147.

Grubb, P.J. (1977) Maintenance of species-richness in plant communities: importance of regeneration niche. Biological Reviews of the Cambridge Philosophical Society, 52, 107-145.

Herrera, J. (1995) Acorn predation and seedling production in a low-density population of cork oak (Quercus suber L.). Forest Ecology and Management, 76, 197-201.

Herrera, C.M., Jordano, P., López-Soria, L. \& Amat, J.A. (1994) Recruitment of a mast-fruiting, bird-dispersed tree: bridging frugivore activity and seedling establishment. Ecological Monographs, 64, 315-344.

Houle, G. (1992) Spatial relationship between seed and seedling abundance and mortality in a deciduous forest of north-eastern North America. Journal of Ecology, 80, 99-108.

Houle, G. (1994) Spatiotemporal patterns in the components of regeneration of four sympatric tree species - Acer rubrum, A. saccharum, Betula alleghaniensis and Fagus grandifolia. Journal of Ecology, 82, 39-53.

Houle, G. (1998) Seed dispersal and seedling recruitment of Betula alleghaniensis: spatial inconsistency in time. Ecology, 79, 807-818.

Hulme, P.E. (1997) Post-dispersal seed predation and the establishment of vertebrate dispersed plants in Mediterranean scrublands. Oecologia, 111, 91-98.

Hulme, P.E. \& Hunt, M.K. (1999) Rodent post-dispersal seed predation in deciduous woodland: predator response to absolute and relative abundance of prey. Journal of Animal Ecology, 68, 417-428.

Janzen, D.H. (1970) Herbivores and the number of the tree species in tropical forests. American Naturalist, 104, 501-528.

Jordano, P. \& Herrera, C.M. (1995) Shuffling the offspring: uncoupling and spatial discordance of multiple stages in vertebrate seed dispersal. Ecoscience, 2, 230-237.

Kelly, D. (1994) The evolutionary ecology of mast seeding. Trends in Ecology \& Evolution, 9, 465-470.

Kelly, D. \& Sork, V.L. (2002) Mast seeding in perennial plants: why, how, where? Annual Review of Ecology and Systematics, 33, 427-447.

Kitajima, K. \& Fenner, M. (2000) Ecology of seedling regeneration. Seeds: The Ecology of Regeneration in Plant Communities (ed. M. Fenner), pp. 331-359. CAB International, London, UK

Kneitel, J.M. \& Chase, J.M. (2004) Trade-offs in community ecology: linking spatial scales and species coexistence. Ecology Letters, 7, 69-80.

Kollmann, J. \& Schill, H.P. (1996) Spatial patterns of dispersal, seed predation and germination during colonization of abandoned grassland by Quercus petraea and Corylus avellana. Vegetatio, 125, 193-205.

Leishman, M.R. \& Westoby, M. (1994) The role of large seed size in shaded conditions: experimental evidence. Functional Ecology, 8, 205-214.

Lloret, F., Casanovas, C. \& Peñuelas, J. (1999) Seedling survival of Mediterranean shrubland species in relation to root: shoot ratio, seed size and water and nitrogen use. Functional Ecology, 13, 210-216. 
MacArthur, R.H. \& Levins, R. (1964) Competition, habitat selection and character displacement. Proceedings of the National Academy of Sciences USA, 51, 1207-1210.

Maltez-Mouro, S., García, L.V. \& Freitas, H. (2009) Influence of forest structure and environmental variables on recruit survival and performance of two Mediterranean tree species (Quercus faginea L. and Q. suber Lam.). European Journal of Forest Research, 128, 27-36.

Mendoza, I., Gómez-Aparicio, L., Zamora, R. \& Matías, L. (2009) Recruitment limitation in a degraded Mediterranean landscape. Journal of Vegetation Science, 20, 367-376.

Metcalfe, D.J. \& Grubb, P.J. (1995) Seed mass and light requirements for regeneration of Southeast Asian rain forest. Canadian Journal of Botany, 73, $817-826$.

Moegenburg, S.M. (1996) Sabal palmetto seed size: causes of variation, choice of predators and consequences for seedlings. Oecologia, 106, 539-543.

Moles, A.T. \& Westoby, M. (2004) Seedling survival and seed size: a synthesis of the literature. Journal of Ecology, 92, 372-383.

Molofsky, J. \& Augspurger, C.K. (1992) The effects of leaf litter on early seedling establishment in a tropical forest. Ecology, 73, 68-77.

Nathan, R. \& Muller-Landau, H.C. (2000) Spatial patterns of seed dispersal, their determinants and consequences for recruitment. Trends in Ecology and Evolution, 15, 278-285.

Norden, N., Chave, J., Belbenoit, P., Caubère, A., Châtelet, P., Forget, P.M., Riéra, B., Viers, J. \& Thébaud, C. (2009) Interspecific variation in seedling responses to seed limitation and habitat conditions for 14 Neotropical woody species. Journal of Ecology, 97, 186-197.

Ojeda, F., Marañón, T. \& Arroyo, J. (2000) Plant diversity patterns in the Aljibe Mountains (S. Spain): a comprehensive account. Biodiversity and Conservation, 9, 1323-1343.

Pausas, J.G., Marañón, T., Caldeira, M. \& Pons, J. (2009) Natural regeneration. Cork Oak Woodlands on the Edge. Ecology, Adaptive Management and Restoration (eds J. Aronson, J.S. Pereira \& J. Pausas), pp. 115-124. Island Press, Washington, DC, USA.

Pérez-Ramos, I.M. (2007) Factores que condicionan la regeneración natural de especies leñosas en un bosque mediterráneo del sur de la Península Ibérica. $\mathrm{PhD}$ thesis, University of Seville, Spain.

Pérez-Ramos, I.M. \& Marañón, T. (2008) Factors affecting postdispersal seed predation in two coexisting oak species: microhabitat, burial and exclusion of large herbivores. Forest Ecology and Management, 255, 3506-3514.

Pérez-Ramos, I.M. \& Marañón, T. (2009) Effects of waterlogging on seed germination of three Mediterranean oak species: ecological implications. Acta Oecologica, 35, 422-428.

Pérez-Ramos, I.M., Marañón, T., Lobo, J.M. \& Verdú, J.R. (2007) Acorn removal and dispersal by the dung beetle Thorectes lusitanicus: ecological implications. Ecological Entomology, 32, 349-356.

Pérez-Ramos, I.M., Zavala, M.A., Marañón, T., Díaz-Villa, M.D. \& Valladares, F. (2008a) Dynamics of understorey diversity following shrub-clearing of cork oak forests: a five-year study. Forest Ecology and Management, 255, $3242-3253$.

Pérez-Ramos, I.M., Urbieta, T.I., Marañón, T., Zavala, M.A. \& Kobe, R.K. (2008b) Seed removal in two coexisting oak species: ecological consequences of seed size, plant cover and seed-drop timing. Oikos, 117, 1386-1396.

Pérez-Ramos, I.M., Gómez-Aparicio, L., Villar, R., García, L.V. \& Marañón, T. (2010) Seedling growth and morphology of three oak species along field resource gradients and seed mass variation: a seedling age-dependent response. Journal of Vegetation Science, 21, 419-437.

Pons, J. \& Pausas, J.G. (2007) Rodent acorn selection in a Mediterranean oak landscape. Ecological Research, 22, 535-541.

Poorter, L. \& Rose, S.A. (2005) Light-dependent changes in the relationship between seed mass and seedling traits: a meta-analysis for rain forest tree species. Oecologia, 142, 378-387.

Pulido, F.J. \& Díaz, M. (2005) Regeneration of a Mediterranean oak: a wholecycle approach. Ecoscience, 12, 92-102.

Purves, D.W., Zavala, M.A., Ogle, K., Prieto, F. \& Rey-Benayas, J.M. (2007) Environmental heterogeneity, bird-mediated directed dispersal, and oak woodland dynamics in Mediterranean Spain. Ecological Monographs, 77, 77-97.

Quero, J.L., Villar, R., Marañón, T. \& Zamora, R. (2006) Interactions of drought and shade effects on seedlings of four Quercus species: physiological and structural leaf responses. New Phytologist, 170, 819-834.

Quero, J.L., Villar, R., Marañón, T., Zamora, R. \& Poorter, L. (2007) Seed-mass effects in four Mediterranean Quercus species (Fagaceae) growing in contrasting light environments. American Journal of Botany, 94, 17951803.
Quero, J.L., Gómez-Aparicio, L., Zamora, R. \& Maestre, F.T. (2008) Shifts in the regeneration niche of an endagered tree (Acer opalus ssp. granatense) during ontogeny: using an ecological concept for application. Basic and Applied Ecology, 9, 635-644.

Quilchano, C., Marañón, T., Pérez-Ramos, I.M., Noejovich, L., Valladares, F. $\&$ Zavala, M.A. (2008) Patterns and ecological consequences of abiotic heterogeneity in managed cork oak forests of southern Spain. Ecological Research, 23, 127-139.

R Development Core Team. (2006) R: A Language and Environment for Statistical Computing v. 2.5.0. R Development Core Team, Vienna, Austria.

Rey, P. \& Alcántara, J.M. (2000) Recruitment dynamics of a fleshy-fruited plant (Olea europaea): connecting patterns of seed dispersal to seedling establishment. Journal of Ecology, 88, 622-633.

Ricklefs, R.E. (1977) Environmental heterogeneity and plant species diversity: a hypothesis. American Naturalist, 111, 377-381.

Santos, T. \& Tellería, J.L. (1997) Vertebrate predation on Holm Oak, Quercus ilex, acorns in a fragmented habitat: effects on seedling recruitment. Forest Ecology and Management, 98, 181-187.

Schupp, E.W. (1995) Seed seedling conflicts, habitat choice, and patterns of plant recruitment. American Journal of Botany, 82, 399-409.

Schupp, E.W. \& Fuentes, M. (1995) Spatial patterns of seed dispersal and the unification of plant population ecology. Ecoscience, 2, 267-275.

Seiwa, K. (2000) Effects of seed size and emergence time on tree seedling establishment: importance of developmental constraints. Oecologia, 123, 208215.

Silvertown, J. (1980) The evolutionary ecology of mast seeding in trees. Biological Journal of the Linnean Society, 14, 235-250.

Silvertown, J. (2004) Plant coexistence and the niche. Trends in Ecology and Evolution, 19, 605-611.

Smith, C.C. \& Fretwell, S.D. (1974) The optimal balance between size and number of offspring. American Naturalist, 108, 499-506.

StatSoft, Inc. (2001) STATISTICA for Windows Computer Program Manual. StatSoft Inc., Tulsa, OK, USA

Traveset, A., Gulias, J., Riera, N. \& Mus, M. (2003) Transition probabilities from pollination to establishment in a rare dioecious shrub species (Rhaтпиs ludovici-salvatoris) in two habitats. Journal of Ecology, 91, 427-437.

Urbieta, T.I., Zavala, M.A. \& Marañón, T. (2008a) Human and non-human determinants of forest composition in southern Spain: evidence of shifts toward cork oak dominance as a result of management over the past century. Journal of Biogeography, 35, 1688-1700.

Urbieta, I.R., Pérez-Ramos, I.M., Zavala, M.A., Marañón, T. \& Kobe, R.K. (2008b) Soil water heterogeneity and emergence time control seedling establishment in three co-occurring oak species. Canadian Journal of Forest Research, 38, 2382-2393.

Urbieta, I.R., García, L.V., Zavala, M.A. \& Marañón, T. (2011) Mediterranean pine and oak distribution in southern Spain: is there a mismatch between regeneration and adult distribution? Journal of Vegetation Science, 22, 18-31.

Verdú, M. \& Traveset, A. (2005) Early emergence enhances plant fitness: a phylogenetically controlled meta-analysis. Ecology, 86, 1385-1394.

Received 27 May 2011; accepted 23 September 2011

Handling Editor: Robert Jones

\section{Supporting Information}

Additional Supporting Information may be found in the online version of this article:

Appendix S1. Summary of the best-fitted models analyzing the variation of stage-specific probabilities of recruitment and seedling growth along the explored range of plant cover (LAI) and seed mass.

As a service to our authors and readers, this journal provides supporting information supplied by the authors. Such materials may be re-organized for online delivery, but are not copy-edited or typeset. Technical support issues arising from supporting information (other than missing files) should be addressed to the authors. 
Appendix 1. Summary of the best-fitted models analyzing the variation of stage-specific

probabilities of recruitment and seedling growth along the explored range of plant cover (LAI) and seed mass. The results of bivariate models in which seed mass was added either additively $(+)$ or multiplicatively $\left({ }^{*}\right)$ are also shown. The signs of the relationships (positive or negative) between each dependent variable and the selected predictors are also indicated, separated by commas.

Bold font denotes models with equivalent empirical support (i.e., $\Delta \mathrm{AIC}<2$ ). LIN, Linear model; EXP, Exponential model; MM, Michaelis-Menten model; LOG, Logistic model; POW, Power model; NULL, Null model.

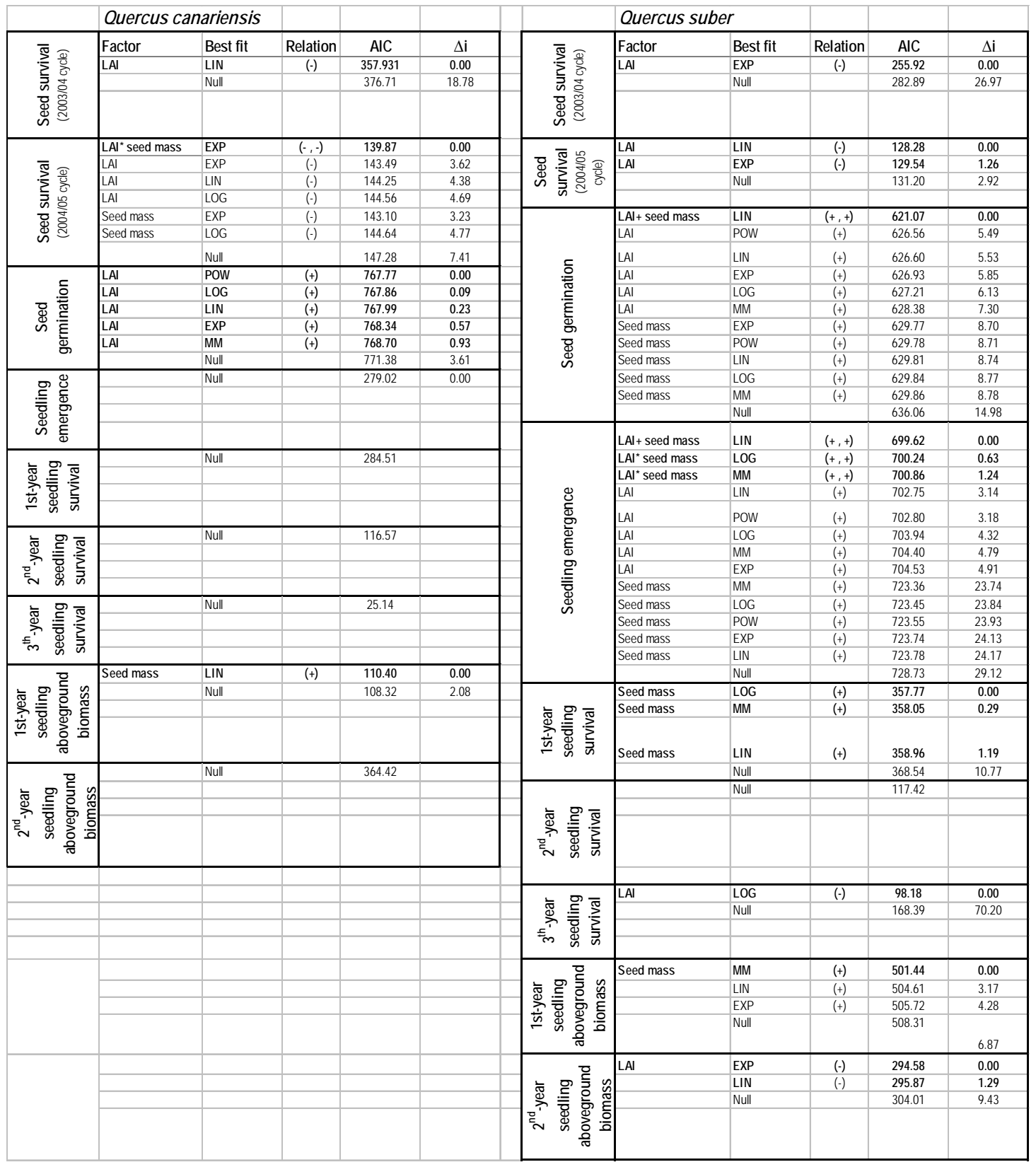

